\title{
A comparative study of complications and long term outcomes of Surgical Tracheostomy and two techniques of Percutaneous Tracheostomy
}

\author{
S. Kiran, S. Eapen, Vivek Chopra
}

Context: The operative technique for surgical tracheostomy has remained unchanged, but different techniques for percutaneous tracheostomy have evolved due to interest in minimally invasive procedures for the critically ill patient. Aims: To compare the periprocedural complications and long term outcomes of bedside surgical tracheostomy (ST) with two percutaneous tracheostomy (PCT) techniques, namely serial guide wire dilating forceps (GWDF) and PercuTwist (PT). Settings and Design: This prospective observational study was carried out in ICU of a tertiary referral centre over three year period on adult intubated patients needing elective tracheostomy. Materials and Methods: Patients with anticipated difficult neck anatomy were assigned for ST based on discretion of intensivist. Patients included for PCT were randomly assigned to the GWDT and PT technique. 90 patients underwent either bedside ST $(n=30)$, PCT by GWDF technique $(n=30)$ or PCT with PercuTwist $(n=30)$ and were followed up with fibreoptic bronchoscopy monthly for 06 months. Statistical Analysis Used: Data was analyzed by applying chi square tests for categorical variables. Results: Periprocedural complications during PCT included major bleeding (>100ml) in two patients in GWDF group which required conversion to ST. Periprocedural bleeding was also the main complication in ST. Increased incidence of granulation tissue and tracheal narrowing in long term was seen in both ST and PCT groups. All of the $P$ values analysed for the intra operative, post operative complications or long term outcomes were $>0.05$. Conclusions: There was no statistically significant difference in incidence of complications of ST and two techniques of PCT. Proper case selection makes PCT as safe as ST.

Keywords: Guidewire dilating forceps, percutaneous tracheostomy complications, percutwist, surgical tracheostomy complications

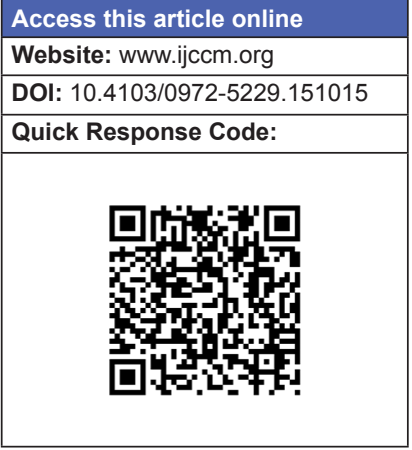

\section{Introduction}

Chevalier Jackson described a standard operative technique for tracheostomy that has remained unchanged for over more than a hundred years. ${ }^{[1]}$ Alternative procedures like different techniques for percutaneous tracheostomy (PCT) have evolved recently due to

From:

Department of Anaesthesiology and Critical Care, Command Hospital (EC), Alipore, Kolkata - 700 027, India

\section{Correspondence:}

Dr. S. Kiran, Classified Specialist (Anaesthesiology) and Critical Care, Department of Anaesthesiology and Critical Care, Command Hospital (EC), Alipore, Kolkata - 700 027, India

E-mail: drkirans@yahoo.com advances in technology and interest in minimally invasive procedures.

The percutaneous dilatational tracheostomy was introduced by Ciaglia in 1985, which involved progressive dilatation with sequentially larger blunt-tipped dilators. ${ }^{[2]}$ In 1990, Griggs added the guidewire dilating forceps (GWDF), a modified Howard-Kelly forceps with blunt edges to this technique. ${ }^{[3]}$ In 2000, Byhahn introduced the Ciaglia Blue Rhino, a modified version of the Ciaglia technique where dilatation of the stoma was done in a single step by means of a hydrophilically coated curved dilator, the Blue Rhino. ${ }^{[4]}$ In 2002, a variation of PCT was introduced by Frova called PercuTwist (PT) 
technique, which involves controlled rotating dilatation using a single screw dilator. ${ }^{[5]}$ Different techniques of PCT are currently used worldwide.

Several studies have compared various techniques of percutaneous tracheostomy (PCT) with standard bedside surgical tracheostomy (ST) as regards to complications and outcomes. Several smaller studies and few meta-analysis on the subject reveal no clear data on the superiority of either technique. In the meta- analysis by Delaney et al., authors feel PCT is the procedure of choice for an elective ICU tracheostomy. ${ }^{[6]}$ The meta-analysis by Higgins et al. illustrated that there is no clear difference but a trend toward fewer complications in percutaneous techniques. ${ }^{[7]}$ We report a study conducted in a tertiary care referral centre comparing periprocedural complications and long term outcomes with surgical tracheostomy (ST) and with two different techniques of PCT, namely GWDF and PT in Intensive Care Unit patients. We hypothesised that the periprocedural complications and long term outcomes of percutaneous tracheostomy (PCT) techniques were comparable to standard bedside surgical tracheostomy (ST) after proper case selection.

\section{Materials and Methods}

The study was conducted by a team which included one intensivist and two ENT surgeons. 90 adult intubated patients in ICU on mechanical ventilation needing elective tracheostomy were included. This prospective observational study was carried out over a three year period.

Paediatric patients, patients with distorted neck anatomy with unidentifiable anatomic landmarks, coagulopathy and patients requiring emergency airway access were excluded from the study. Patients with anticipated difficult neck anatomy were assigned for ST based on discretion of intensivist. Other patients were assigned to the PCT group. Patients once included for PCT were randomly assigned to the GWDT and PT technique. After 30 patients each underwent two techniques of PCT, rest of the patients who underwent PCT in the ICU were not included in the study. The study continued till 30 patients considered fit only for ST by the intensivist, underwent tracheostomy using the ST technique.

Patients underwent bedside ST $(n=30)$, PCT by GWDF technique $(n=30)$ and PCT with PT technique $(n=30)$. All cases of surgical tracheostomy were operated by the ENT surgeon at the bedside with use of surgical cautery. Cuffed tracheostomy tube (Portex ${ }^{\circledR}$ ) $7.0 \mathrm{~mm}$ ID was inserted in all cases after surgical dissection. PCT with GWDF was accomplished with Portex® Griggs Forceps Percutaneous Dilation Tracheostomy Kits size $7.0 \mathrm{~mm}$ ID. PCT with PercuTwist single stage dilator technique was performed with PercuTwist Percutaneous Dilatation Tracheosptomy set (PercuTwist PDT ${ }^{\circledR}$, RUSCH) size $7.0 \mathrm{~mm}$ ID. All the procedures were carried out under sedation with propofol and local anaesthetic infiltration in intubated and mechanically ventilated patients. The desired puncture site was the second and third tracheal rings and was determined with anatomical landmarks. The endotracheal tube was withdrawn till the cuff was barely visible at the vocal cords and mechanical ventilation was continued throughout the procedure. All cases of PCT were carried out under fibreoptic bronchoscopy passed through the endotracheal tube for visual confirmation of each step. Periprocedural complications were noted and effectively managed. All patients were followed up and decannulation was attempted at the earliest opportunity. All patients who survived, underwent a fibreoptic bronchoscopy before and after decannulation and at 30 days and monthly thereafter for a period of 06 months to look for long term complications.

\section{Statistical analysis}

Data was analyzed using SPSS software version 16 and chi square tests were applied for categorical variables. Data are expressed in terms of mean +/-SD. Sample size was calculated based on literature search for variation in studied data and based on the predicted number of patients likely to be available in our tertiary care ICU for inclusion in the study over a three year period. Data was analyzed by applying chi square tests for categorical variables. Data was also expressed in terms of percentages. $P$ value was reported at the $95 \%$ confidence interval and $P$ value less than 0.05 was considered significant.

\section{Results}

Out of 90 adult patients on long-term mechanical ventilation included in the study there were 60 male and 30 female patients. Out of the 60 patients who underwent PCT there were 42 males and 18 females [Table 1]. Majority of the patients were of head injury (21 patients) and cerebrovascular accidents (40 patients). Difficult wean was the cause in 10 patients [Table 2]. There was no statistically significant difference in patient characteristics in the three groups $(P>0.05)$. The decision to perform tracheostomy was taken within 5 to 15 days of endotracheal intubation depending on the expected outcome of the patients. The mean duration of the PCT from skin incision to successful insertion of tracheostomy 
tube by GDWF was 13.5 minutes and by PT technique was 11.5 minutes. The mean duration was 22.6 minutes for surgical tracheostomy [Table 3].

Intraoperatively 02 patients of ST had major bleeding defined as more than $100 \mathrm{ml}$ blood loss, which was easily controlled by cautery. Two patients of GWDF group had major bleeding which required conversion to ST and sutures to control bleeding. This also led to hypotension and desturation in both patients due to bleed into the trachea and endotracheal tube. Among other preoperative complications two patients who underwent PT had chip fracture of tracheal cartilage ring. One patient has a false passage and kinking of guidewire in the GWDF group which required change of guidewire and resinsertion [Table 4].

Among postoperative complications two patients of ST had minor bleeding defined as bleeding less than $100 \mathrm{ml}$, which was managed conservatively with stomal packs. Subcutaneous emphysema was noticed in two patients of ST. One patient had excessive purulent exudate at stoma in the ST group. In the GWDF group 03 patients had hematoma formation which was managed conservatively. In the PT group 02 patients had hematoma formation and 02 patients developed small subcutaneous emphysema which was managed conservatively [Table 5].

Successful decannulation was achieved in 26 patients $(28.8 \%)$. Progression to permanent tracheostomy occurred in 12 cases $(13.3 \%)$. Wound approximation by surgery was required in one patient $(1.1 \%)$ after decannulation in the ST group. 45 patients $(50 \%)$ died as a consequence of the primary disease. Six patients $(6.6 \%)$ were lost to follow up. A total $13(14.4 \%)$ patients had narrowing of trachea and excessive granulations as seen on FOB at decannulation or at 30 days. Two patients of ST group and one patient each of the GWDF group and PT group required microlaryngeal surgical laser resection of the granulations to facilitate deccanulation. One patient in the PT group had a small tracheoesophageal fistula [Table 6].

All of the $P$ values analysed for the intra operative, post operative complications or long term outcomes were $>0.05$.

\section{Discussion}

This study which compared incidence of complications and long term outcomes after ST versus two techniques of PCT showed that there is no statistically significant

\begin{tabular}{|c|c|c|c|c|}
\hline \multirow{2}{*}{$\begin{array}{l}\text { Technique of } \\
\text { tracheostomy }\end{array}$} & \multirow{2}{*}{$\begin{array}{c}\text { No of } \\
\text { patients }\end{array}$} & \multicolumn{2}{|c|}{ Sex of patients } & \multirow[t]{2}{*}{$P$} \\
\hline & & Male & Female & \\
\hline Surgical technique & 30 & 18 & 12 & 0.55 \\
\hline GWDF technique & 30 & 20 & 10 & \\
\hline PercuTwist technique & 30 & 22 & 8 & \\
\hline
\end{tabular}

GWDF: Guide wire dilating forceps

Table 2: Patient characteristics (primary diagnosis) ( $n=30$ each)

\begin{tabular}{|c|c|c|c|c|c|}
\hline Diagnosis & $\begin{array}{l}\text { Surgical } \\
\text { technique }\end{array}$ & $\begin{array}{l}\text { GWDF } \\
\text { technique }\end{array}$ & $\begin{array}{l}\text { PercuTwist } \\
\text { technique }\end{array}$ & Total & $P$ \\
\hline Traumatic brain injury & 7 & 7 & 7 & 21 & 1.0 \\
\hline Cerebrovascular accident & 13 & 14 & 13 & 40 & 0.96 \\
\hline $\begin{array}{l}\text { Other neurological } \\
\text { conditions, spinal cord } \\
\text { and neuromuscular } \\
\text { disorders }\end{array}$ & 2 & I & 1 & 4 & 0.76 \\
\hline $\begin{array}{l}\text { Sepsis with multiorgan } \\
\text { failure }\end{array}$ & 2 & 2 & I & 5 & 0.81 \\
\hline Underlying malignancy & 3 & 2 & I & 6 & 0.59 \\
\hline Chronic kidney disease & I & 2 & I & 4 & 0.77 \\
\hline $\begin{array}{l}\text { Chronic obstructive } \\
\text { pulmonary disease }\end{array}$ & 3 & $\mathrm{I}$ & 6 & 10 & 0.12 \\
\hline
\end{tabular}

GWDF: Guide wire dilating forceps

Table 3: Mean duration taken for procedure in minutes $(n=30)$

Technique of tracheostomy

Surgical technique 22.6

GWDF technique $\quad 13.5$

PercuTwist technique

11.5

GWDF: Guide wire dilating forceps

Table 4: Intra-operative complications ( $n=30$ each)

\begin{tabular}{lccccc}
\hline Complication & $\begin{array}{c}\text { ST } \\
(\%)\end{array}$ & $\begin{array}{c}\text { GWDF } \\
\text { technique } \\
(\%)\end{array}$ & $\begin{array}{c}\text { PercuTwist Percentage } \\
\text { technique } \\
(\%)\end{array}$ & $P$ \\
\hline $\begin{array}{l}\text { Major bleeding } \\
\text { (>I00 ml) }\end{array}$ & $2(2.2)$ & $2(2.2)$ & - & 4.4 & 0.35 \\
$\begin{array}{l}\text { False passage/ } \\
\text { kinking of GW }\end{array}$ & - & $\mathrm{I}(\mathrm{I} . \mathrm{I})$ & - & $\mathrm{I}) \mathrm{I}$ & 0.96 \\
$\begin{array}{l}\text { Oxygen desaturation } \\
\text { Hypotension }\end{array}$ & - & $2(2.2)$ & - & 2.2 & 0.85 \\
$\begin{array}{l}\text { Fracture of tracheal } \\
\text { ring }\end{array}$ & - & $2(2.2)$ & - & 2.2 & 0.85 \\
$\begin{array}{l}\text { Damage to posterior } \\
\text { tracheal wall }\end{array}$ & - & - & $2(2.2)$ & 2.2 & 0.85 \\
GWDF: Guide wire dilating forceps; ST: Surgical tracheostomy; GW: Guidewire
\end{tabular}

Table 5: Post-operwative complications ( $n=30$ each)

\begin{tabular}{|c|c|c|c|c|c|}
\hline Complication & $\begin{array}{l}\text { ST } \\
\text { (\%) }\end{array}$ & $\begin{array}{c}\text { GWDF } \\
\text { technique } \\
(\%)\end{array}$ & $\begin{array}{c}\text { PercuTwist } \\
\text { technique } \\
(\%)\end{array}$ & Percentage & $P$ \\
\hline $\begin{array}{l}\text { Minor bleeding/ } \\
\text { hematoma }\end{array}$ & $2(2.2)$ & $3(3.3)$ & $2(2.2)$ & 7.7 & 0.86 \\
\hline Surgical emphysema & $2(2.2)$ & - & $2(2.2)$ & 4.4 & 0.35 \\
\hline Wound infection & I (I.I) & - & - & I.I & 0.9 \\
\hline Tube displacement & - & - & - & Nil & - \\
\hline Pneumothorax & - & - & - & Nil & - \\
\hline
\end{tabular}

GWDF: Guide wire dilating forceps; ST: Surgical tracheostomy 


\begin{tabular}{|c|c|c|c|c|c|}
\hline \multicolumn{6}{|c|}{ Table 6: Long term outcome of patients ( $n=30$ each) } \\
\hline Outcome & $\begin{array}{l}\text { ST } \\
(\%)\end{array}$ & $\begin{array}{c}\text { GWDF } \\
\text { technique } \\
(\%)\end{array}$ & $\begin{array}{c}\text { PercuTwist } \\
\text { technique } \\
(\%)\end{array}$ & $\begin{array}{c}\text { Total } \\
\text { percentage }\end{array}$ & $\mathbf{P}$ \\
\hline $\begin{array}{l}\text { Successful } \\
\text { decannulation }\end{array}$ & $\mathrm{II}(\mathrm{I} 2.2)$ & $8(8.8)$ & $7(7.7)$ & 28.8 & 0.49 \\
\hline $\begin{array}{l}\text { Permanent/ } \\
\text { long term } \\
\text { tracheostomy }\end{array}$ & $3(3.3)$ & $3(3.3)$ & $6(6.6)$ & 13.3 & 0.42 \\
\hline $\begin{array}{l}\text { Surgical closure } \\
\text { of stoma }\end{array}$ & $\mathrm{I}(\mathrm{I} . \mathrm{I})$ & - & - & 1.1 & - \\
\hline $\begin{array}{l}\text { Excessive } \\
\text { granulations/ } \\
\text { narrowing } \\
\text { of trachea/ } \\
\text { tracheoesophageal } \\
\text { fistula }\end{array}$ & $6(6.6)$ & $3(3.3)$ & $4(4.4)$ & 14.4 & 0.53 \\
\hline Lost to follow up & $2(2.2)$ & $\mathrm{I}(\mathrm{I} . \mathrm{I})$ & $3(3.3)$ & 6.6 & 0.59 \\
\hline $\begin{array}{l}\text { Died due to } \\
\text { primary disease }\end{array}$ & $13(14.4)$ & $18(20)$ & $14(15.5)$ & 50 & 0.39 \\
\hline
\end{tabular}

difference between the different techniques. PCT is an established procedure for airway management in critically ill patients who require long-term respiratory support and has replaced the ST as the primary bedside technique in intensive care units. Though the incidence of complications with PCT varies with the different techniques used, incidence of bleeding and other complications are less compared to open surgical technique as published by Griggs et al. ${ }^{[3]}$ Recent meta-analyses also show a trend towards lesser complications with PCT. ${ }^{[6,7]}$

Some authors have suggested use of fibreoptic bronchoscope (FOB) to reduce the procedural complications. This has been mainly due to the fact that FOB can help to verify the safe placement of needle and guide wire and to avoid trauma to posterior tracheal wall during dilatation. ${ }^{[8]}$ In this study, PCT using GWDF and PT technique were both performed with the aid of FOB. The placement of needle in the trachea was confirmed by free aspiration of air as well as by FOB. In addition the free movement of guide wire at each stage of the procedure was taken as prerequisite for proceeding further. With bronchoscopic assistance, the tip of the ETT, the needle puncture site in the midline of the trachea and dilatation of the tracheal stoma was visualized. Adherence to these simple steps led to successful and accurate placement of tracheostomy tube in all patients of PCT with minimal major complications.

Major bleeding was the main life threatening complication for all the techniques. Two incidences each of major bleeding, desaturation and hypotension which occurred with PCT with GWDF, was due to vascular puncture near the isthmus of the thyroid by the initial dilators prior to the use of dilating forceps. Neck ultrasound performed prior to PCT may be useful in avoiding injury to pretracheal vascular structures. Also real time ultrasound guidance with visualization of needle path may enhance the safety and accuracy of PCT. ${ }^{[9]}$

Endotracheal tube cuff puncture occurred in several cases of both ST and PCT but did not lead to significant loss of ventilation, aspiration or desaturation. The only significant complication encountered during PT was fracture of tracheal ring which has been earlier reported by Scherrer et al. ${ }^{[10]}$

Late complications like left sided vocal cord paralysis, hoarseness of voice and voice change was checked for at one month, but were absent in all cases. Abnormal granulation tissue revealed by an FOB examination performed one month after tracheostomy was present in $4 \%$ to $6 \%$ of cases among all groups, two of which required microlaryngeal surgical laser resection of the granulations to facilitate decannulation. This is in concurrence with the study by Melloni et al. which showed late tracheal complications were more prevalent in the PCT group, but was not statistically significant. ${ }^{[11]}$

PCT is a well established technique used in the critical care setting. It is an elective procedure, not suitable for the emergency airway. Although the technique may be performed blind, visualisation with FOB increases margin of safety. PCT technique is safe, quick, with low rate of complications and long term outcomes comparable to surgical tracheostomy. Proper case selection makes PCT as safe as ST. Use of ultrasound guidance for vascular structures may benefit as the main complication encountered is that of periprocedural bleeding.

\section{Acknowledgement}

Department of ENT, Command Hospital (EC), Alipore, Kolkata - 700 027, India.

\section{References}

1. Jackson C. Tracheostomy. Laryngoscope 1909;19:285-90.

2. Ciaglia P, Firsching R, Syniec C. Elective percutaneous dilatational tracheostomy: A new simple bedside procedure-preliminary report. Chest 1985;87:715-9.

3. Griggs WM, Myburgh JA, Worthley LI. A prospective comparison of a percutaneous tracheostomy technique with standard surgical tracheostomy. Intensive Care Med 1991;17:261-3.

4. Byhahn C, Wilke HJ, Halbig S, Lischke V, Westphal K. Percutaneous 
tracheostomy: Ciaglia Blue Rhino versus the basic Ciaglia technique of percutaneous dilational tracheostomy. Anaesth Analg 2000;91:882-6.

5. Frova G, Quintel M. A new simple method for percutaneous tracheostomy: Controlled rotating dilation. Intensive Care Med 2002;28:299-303.

6. Delaney A, Bagshaw SM, Nalos M. Percutaneous dilatational tracheostomy versus surgical tracheostomy in critically ill patients: A systematic review and meta-analysis. Crit Care 2006;10:R55.

7. Higgins KM, Punthakee X. Meta-analysis comparison of open versus percutaneous tracheostomy. Laryngoscope 2007;117:447-54.

8. Atweh NA, Possenti PP, Caushaj PF, Burns G, Pineau MJ, Ivy M. Dilational percutaneous tracheostomy: Modification of technique. J Trauma 1999;47:142-4.

9. Rajajee V, Fletcher JJ, Rochlen LR, Jacobs TL. Real-time ultrasound-guided percutaneous dilatational tracheostomy: A feasibility study. Crit Care 2011;15:R67.

10. Scherrer E, Tual L, Dhonneur G. Tracheal ring fracture during a PercuTwist tracheostomy procedure. Anaesth Analg 2004;98:1451-3.

11. Melloni G, Muttini S, Gallioli G, Carretta A, Cozzi S, Gemma M, et al. Surgical tracheostomy versus percutaneous dilatational tracheostomy: A prospective randomized study with long-term follow-up. J Cardiovasc Surg (Torino) 2002;43:113-21.

How to cite this article: Kiran S, Eapen S, Chopra V. A comparative study of complications and long term outcomes of Surgical Tracheostomy and two techniques of Percutaneous Tracheostomy. Indian J Crit Care Med 2015;19:82-6.

Source of Support: Nil, Conflict of Interest: None declared.

\section{New features on the journal's website}

\section{Optimized content for mobile and hand-held devices}

HTML pages have been optimized of mobile and other hand-held devices (such as iPad, Kindle, iPod) for faster browsing speed.

Click on [Mobile Full text] from Table of Contents page.

This is simple HTML version for faster download on mobiles (if viewed on desktop, it will be automatically redirected to full HTML version)

\section{E-Pub for hand-held devices}

EPUB is an open e-book standard recommended by The International Digital Publishing Forum which is designed for reflowable content i.e. the text display can be optimized for a particular display device.

Click on [EPub] from Table of Contents page.

There are various e-Pub readers such as for Windows: Digital Editions, OS X: Calibre/Bookworm, iPhone/iPod Touch/iPad: Stanza, and Linux: Calibre/Bookworm.

\section{E-Book for desktop}

One can also see the entire issue as printed here in a 'flip book' version on desktops. Links are available from Current Issue as well as Archives pages.

Click on View as eBook 